\title{
Volcanic magma reservoir imaged as a low-density body beneath Aso volcano that terminated the 2016 Kumamoto earthquake rupture
}

\author{
Ayumu Miyakawa ${ }^{1 *} \mathbb{0}$, Tatsuya Sumita ${ }^{1}$, Yasukuni Okubo ${ }^{1}$, Ryo Okuwaki², Makoto Otsubo ${ }^{1}$, Shimpei Uesawa ${ }^{3}$ \\ and Yuji Yagi ${ }^{4}$
}

\begin{abstract}
We resolve the density structure of a possible magma reservoir beneath Aso, an active volcano on Kyushu Island, Japan, by inverting gravity data. In the context of the resolved structure, we discuss the relationship between the fault rupture of the 2016 Kumamoto earthquake and Aso volcano. Low-density bodies were resolved beneath central Aso volcano using a three-dimensional inversion with an assumed density contrast of $\pm 0.3 \mathrm{~g} / \mathrm{cm}^{3}$. The resultant location of the southern low-density body is consistent with a magma reservoir reported in previous studies. No Kumamoto aftershocks occur in the southern low-density body; this aseismic anomaly may indicate a ductile feature due to high temperatures and/or the presence of partial melt. Comparisons of the location of the southern low-density body with rupture models of the mainshock, obtained from teleseismic waveform and InSAR data, suggest that the rupture terminus overlaps the southern low-density body. The ductile features of a magma reservoir could have terminated rupture propagation. On the other hand, a northern low-density body is resolved in the Asodani area, where evidence of current volcanic activity is scarce and aftershock activity is high. The northern low-density body might, therefore, be derived from a thick caldera fill in the Asodani area, or correspond to mush magma or a high-crystallinity magma reservoir that could be the remnant of an ancient intrusion.
\end{abstract}

Keywords: 2016 Kumamoto earthquake, Density structure, Gravity inversion, Volcano-tectonic interactions

\section{Background}

The 2016 Kumamoto earthquake $\left(M_{\mathrm{IMA}} 7.3\right)$ occurred on April 16, 2016, at 01:25 Japan Standard Time (JST, UTC $+9)$ in the Kumamoto region, Kyushu Island, southwestern Japan. The epicenter $\left(32.76^{\circ} \mathrm{N}, 130.76^{\circ} \mathrm{E}\right)$ and hypocentral depth (12 km below sea level) determined by the Japan Meteorological Agency (JMA) are very close to Aso volcano, the largest active volcano with a large caldera $(15 \times 25 \mathrm{~km})$ in Japan (Fig. 1). The rupture process of the 2016 Kumamoto earthquake was resolved by Yagi et al. (2016): Rupture initiated at the hypocenter on the

\footnotetext{
*Correspondence: miyakawa-a@aist.go.jp

${ }^{1}$ Geological Survey of Japan, AIST, 1-1-1 Higashi, Tsukuba, Ibaraki 3058567, Japan

Full list of author information is available at the end of the article
}

southwest part of the focal plane and propagated east for about $17 \mathrm{~s}$. The area of maximum slip, with a value of $\sim 5.7 \mathrm{~m}$, was centered $\sim 10 \mathrm{~km}$ northeast of the epicenter. The effective slip area was about $40 \mathrm{~km}$ long and $15 \mathrm{~km}$ wide, and the total seismic moment was $5.1 \times 10^{19} \mathrm{Nm}$ $\left(M_{\mathrm{w}}=7.0\right)$. Aftershock distributions and focal mechanism determined by Yagi et al. (2016) indicate that the 2016 Kumamoto earthquake occurred along an active strike-slip fault known as the Futagawa Fault (Research Group for Active Faults of Japan 1991), which belongs to the Oita-Kumamoto Tectonic Line (OKTL) (e.g., Kamata and Kodama 1994) and comprises the principal shear zone on Kyushu island (Matsumoto et al. 2015). Rupture propagation terminated near the southwest side of Aso volcano (Yagi et al. 2016); co-seismic surface deformation observed by Interferometric Synthetic Aperture 


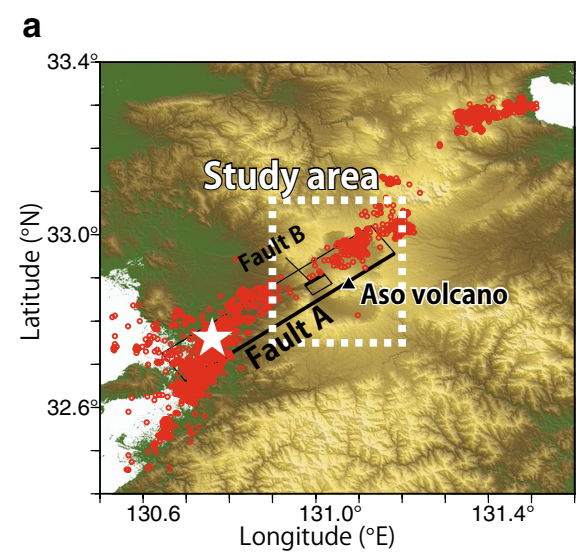

b

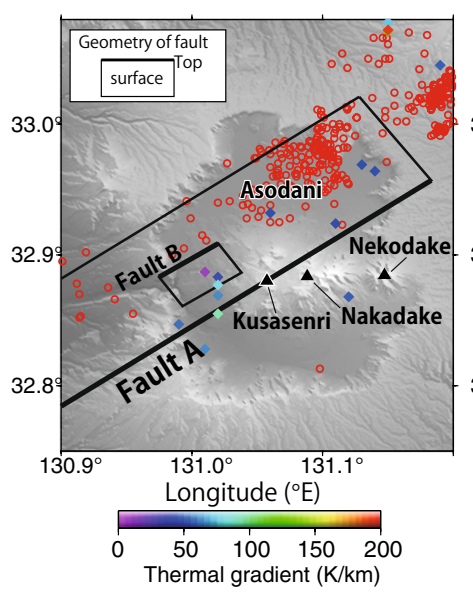

c

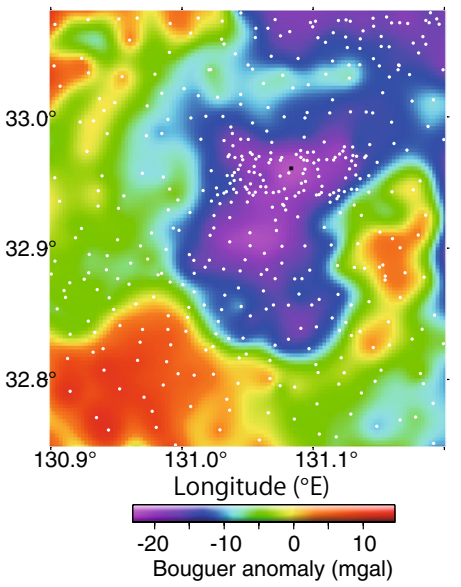

Fig. 1 Epicenter and aftershocks of the 2016 Kumamoto earthquake and Bouguer anomaly of the study area. a Epicenter and aftershocks of the 2016 Kumamoto earthquake as determined by the Japan Meteorological Agency (JMA). The white star indicates the epicenter of the main shock. Also shown are aftershocks that occurred in the first 3 days after the mainshock (red circles). Solid black rectangles (Faults A and B) indicate surface projections of fault geometries determined by Yagi et al. (2016) and Geospatial Information Authority of Japan (2016b), respectively (Table 1). b Topography of the study area. Red circles and solid black rectangles indicate aftershocks and fault geometries, respectively, as in (a). Diamonds indicate geothermal gradient (Tanaka et al. 2004). c Bouguer anomaly of the study area. The Bouguer anomaly is calculated with a reduced density of $2.3 \mathrm{~g} / \mathrm{cm}^{3}$. White dots indicate the reference point used to calculate the Bouguer anomaly and for the gravity inversion (Fig. 2)

Radar (InSAR) also clearly terminated at Aso volcano (e.g., Geospatial Information Authority of Japan 2016a, b) (Additional file 1: Figure S1). These observations suggest that Aso volcano influenced the rupture. Consequently, the relationship between the 2016 Kumamoto earthquake and Aso volcano can be studied as an example of interactions between fault rupture during large earthquakes and active volcanoes.

Aso volcano formed through a series of four large explosive eruptions at ca. 70,000-80,000 years ago (Ono and Watanabe 1985). Central Kyushu, where Aso volcano is located, is characterized by a high heat flow (Ehara, 1984). Magnetic anomaly data suggest the existence of a high-temperature zone $\left(T>500{ }^{\circ} \mathrm{C}\right)$ around Aso (Okubo and Shibuya 1993; Okubo et al. 1997). Temperatures below $1500 \mathrm{~m}$ depth are estimated to be $>200{ }^{\circ} \mathrm{C}$ in the Yunotani region (New Energy and Industrial Technology Development Organization 1996). However, the detailed thermal structure around Aso volcano is poorly understood, although some thermal gradient measurements have been undertaken in the area (e.g., Tanaka et al. 2004). Fumarolic activity has been continuously observed at Nakadake cone, the only active caldera cone in Aso volcano (e.g., Mori and Notsu 2008). A zone of low seismic velocity at $5-6 \mathrm{~km}$ below Nakadake has been previously interpreted as a shallow magma reservoir (Sudo and Kong 2001). The location of a modeled deflation source beneath Kusasenri area, resolved from ground deformation data, coincides with a low-velocity zone that may represent the magma reservoir (Sudo et al. 2006). Aso volcano erupted at Nakadake on October 8, 2016, at 01:46 JST (Japan Meteorological Agency 2016a), though there has been no remarkable activity at Aso volcano during the $4+$ months since the 2016 Kumamoto earthquake except for very small eruptions on April 16 and May 1, 2016 (Japan Meteorological Agency 2016b, c). The large eruption on October 8, 2016, which sent a column of smoke and ash $11,000 \mathrm{~m}$ into the air, was the largest eruption of Aso volcano in 36 years (Japan Meteorological Agency 2016a).

Table 1 Geometry of Aso area faults

\begin{tabular}{|c|c|c|c|c|c|c|c|}
\hline & Longitude $\left({ }^{\circ}\right)$ & Latitude $\left({ }^{\circ}\right)$ & Depth to top (km) & Length (km) & Width (km) & Strike $\left({ }^{\circ}\right)$ & $\operatorname{Dip}\left({ }^{\circ}\right)$ \\
\hline Fault $A^{a}$ & 131.183 & 32.957 & -0.9 & 56 & 18 & 234 & 64 \\
\hline Fault $B^{b}$ & 130.975 & 32.883 & 0.2 & 5.1 & 6.6 & 56 & 62 \\
\hline
\end{tabular}

Coordinates correspond to the top-left part of each fault model

a Yagi et al. (2016)

b Geospatial Information Authority of Japan (2016b) 

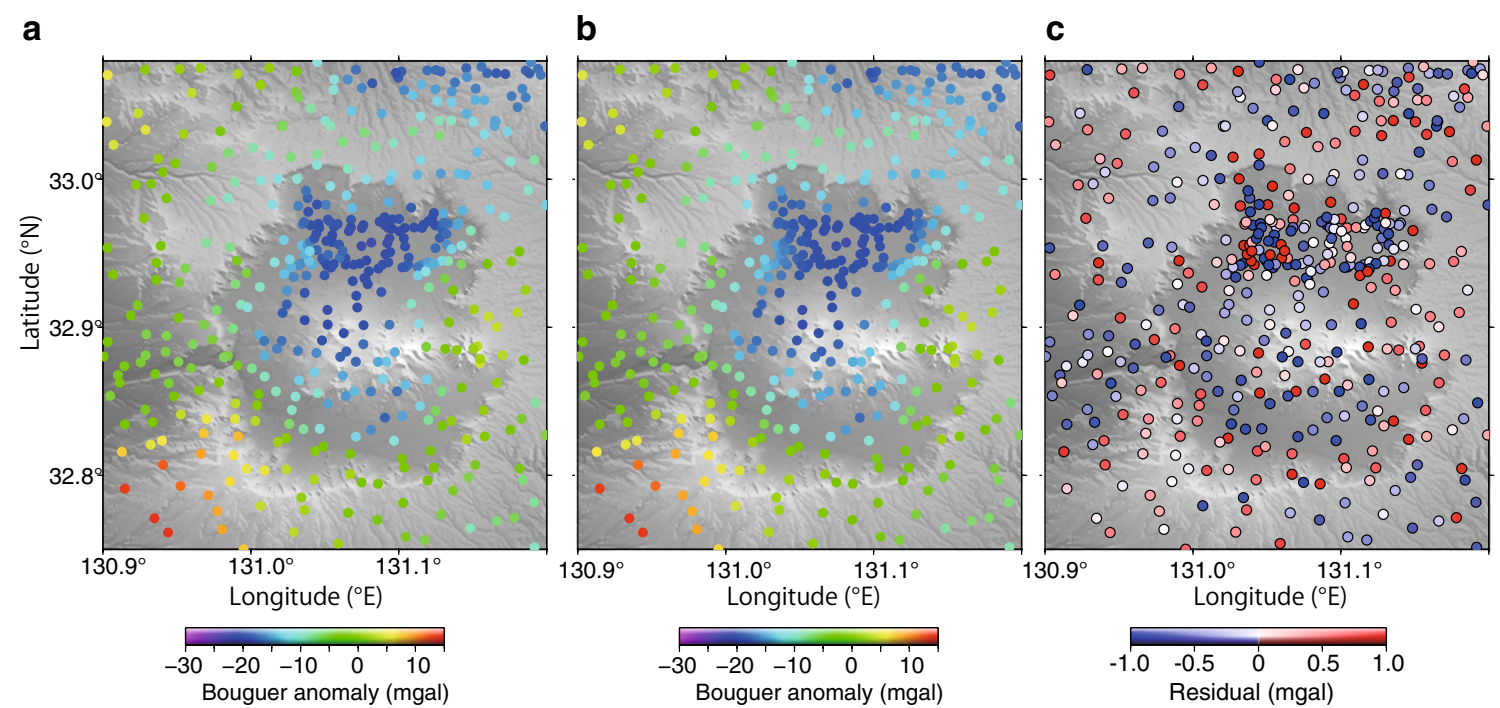

Fig. 2 Comparison between observed and modeled Bouguer anomalies. a Observed, b modeled, c residuals at measurement points

The principal aim of this study is to discuss the relationship between the 2016 Kumamoto earthquake and volcanic structures at Aso, as inferred from the density structure beneath Aso volcano. Previous gravity studies have revealed the existence of low-density bodies at Aso volcano at depths of $>5 \mathrm{~km}$ below sea level (Komazawa 1995). One such body is situated in nearly the same location as a zone of high seismic attenuation discovered by Sudo $(1988,1991)$ and is thought to relate to a shallow reservoir of partial melt (Komazawa 1995; Sudo and Kong 2001). However, the three-dimensional shape of the deep low-density body beneath Aso volcano remains poorly understood, because the only previous gravity study (Komazawa 1995) conducted a two-dimensional inversion along just a single profile (NW-SE). We resolve the low-density body in three dimensions using a gravity inversion based on the method of Camacho et al. (2011) and discuss the relationship between the 2016 Kumamoto earthquake and the inferred magma reservoir.

\section{Data and methods}

Our data set consists of gravity data compiled by the Geological Survey of Japan (Komazawa et al. 2013; New Energy and Industrial Technology Development Organization 2013; Metal Mining Agency of Japan 2013). All measured gravity data were referenced to the Japan Gravity Standardization Net 1971 (JGSN75), which is based on the International Gravity Standardization Net 1971 (IGSN71); normal gravities were estimated using Gravity Formula 1980. The WGS-84 datum, based on the GRS80 ellipsoid, was used for all calculations. The procedure involves a calculation scheme with formulations for normal gravity, free-air reduction, atmospheric correction, lithospheric correction, and Bouguer correction (Komazawa 1998). A terrain correction was applied by assuming an annular prism model (Komazawa 1988) with digital elevation model (DEM) data, supplied by the Geospatial Information Authority of Japan. The mesh size of the DEM used here is $250 \mathrm{~m}$ for the far field and $50 \mathrm{~m}$ for the near field, ensuring sufficient accuracy for the inversion. These corrections guarantee an accuracy of $\sim 0.5 \mathrm{mGal}$ (Geological Survey of Japan 2013). The density of the surface layer in the area around Aso volcano was estimated to be $2.2-2.3 \mathrm{~g} / \mathrm{cm}^{3}$ by Komazawa (1995). Thus, a value of $2.3 \mathrm{~g} / \mathrm{cm}^{3}$ was used to compute the Bouguer and terrain corrections in this study. The Bouguer gravity anomaly map is depicted in Fig 1c. A total of 512 measurements of observed gravity data were selected for the inversion (Figs. 1c, 2a). The study area is small enough that regional trends (e.g., related to the subducting Philippine Sea Plate) can be neglected. Thus, we assumed a homogeneous density profile for the background; i.e., we did not remove regional trends from the observed gravity field before conducting the inversion.

The gravity inversion was conducted primarily to resolve the geometry of the low-density body or bodies that produce the observed gravity field. We employed the three-dimensional gravity inversion technique of Camacho et al. (2011), which can invert for arbitrarily shaped anomaly structures by treating them as composites of multiple bodies with simple geometries. The method requires prescribed density contrasts, a homogeneity parameter, a balance factor, and a grid size. The homogeneity parameter defines the pattern of density 
transitions across the boundaries of anomalous bodies. For high values of the homogeneity parameter, the boundaries appear smoothed and diluted, with densities close to extremal values found toward the center of the body and decreasing toward the periphery (see Camacho et al. 2011 for details). The balance factor defines model smoothness. We determined an optimal value for the balance factor that satisfies the conditions of zero autocorrelations among residuals with respect to mutual distances between measurement points (Camacho et al. 2007). The reason for adopting this balance factor is the assumption that an essential characteristic of the noise is the lack of a spatial correlation between values; indeed, correlated signals would constitute significant components, worthy of inversion (Camacho et al. 2007).

\section{Results and discussion}

\section{Parameters for the gravity inversion}

We selected the following parameters by assuming a general melt-rich magma reservoir, since the exact properties beneath Aso volcano are unclear. The prescribed densities are $-0.3 \mathrm{~g} / \mathrm{cm}^{3}$ for low-density bodies, $+0.3 \mathrm{~g} /$ $\mathrm{cm}^{3}$ for high-density bodies, and $0 \mathrm{~g} / \mathrm{cm}^{3}$ for neutraldensity bodies (i.e., the background). This density contrast is assumed to represent the low-density material as a mixture of $50 \%$ melt with some gas and $50 \%$ solid crystals, at which ratio the rheology shifts from viscous to rigid (Marsh 1996). At the same time, we considered basaltic andesite and granite to represent the high- and moderate-density material, respectively. The homogeneity parameter is 0.2 , which results in abrupt transitions in density across the boundaries of the resultant anomalous bodies, e.g., the boundary between a magma reservoir and the surrounding rock. The mean grid length in the inversion model was set to $500 \mathrm{~m}$; this is the finest grid size that can be inverted in a reasonable amount of computing time using our algorithm and hardware (using an Intel Xeon E5-1620 CPU with 16.0 GB RAM). The bottom and top of the model were set to $15 \mathrm{~km}$ below sea level and $0.6 \mathrm{~km}$ above sea level, respectively. The optimal value determined for the balance factor was 47.46.

With the parameters given above, the calculated model produces a synthetic gravity field that is a good fit to the observed gravity field (Fig. 2). The standard deviation of $0.74 \mathrm{mGal}$ for the residual values is comparable to the inherent inaccuracy in the gravity measurements themselves. The large misfit values are located mainly in the densely sampled area of Asodani. This could have been caused by a short-wavelength Bouguer anomaly derived from shallow, fine-scale density structures, smaller than the grid size of the inversion model; however, shallow, ultra-fine-scale features are not the focus of this study.
We performed gravity inversions with several parameter sets to investigate the robustness of the inversion result with respect to parameter choices (i.e., prescribed density contrasts, homogeneity, and mean grid length). Variations in parameters are tested one by one, based on the basic model (i.e., $\pm 0.3 \mathrm{~g} / \mathrm{cm}^{3}$, homogeneity parameter 0.2 , and mean grid length $500 \mathrm{~m}$ ). Density contrasts tested include variations of $\pm 0.15, \pm 0.20, \pm 0.25, \pm 0.35$, and $\pm 0.40 \mathrm{~g} / \mathrm{cm}^{3}$ (Additional file 2: Figure S2; Additional file 4: Table S1); homogeneity parameters tested include 0.4, 0.6, and 0.8 (Additional file 3: Figure S3; Additional file 5: Table S2); and mean grid lengths tested include 750 and $1000 \mathrm{~m}$ (Additional file 4: Figure S4; Additional file 5: Table S3).

The result of the gravity inversion with several parameter sets revealed the robustness of the central position and the shape of the gravity anomaly, although the density contrast, homogeneity, and grid size affect the apparent size of the density anomaly, its sharpness, and the model resolution, respectively. Therefore, we conclude that the location of the density anomaly is robust with respect to our gravity inversion, although the exact boundaries of the density anomaly can be changed somewhat by varying the input parameters.

\section{Density structures and their interpretations}

Our gravity inversion imaged both low- and high-density structures beneath Aso volcano (Fig. 3). The horizontal location of the low-density structure beneath Kusasenri, Nakadake, and Asodani is consistent with the low-density body resolved by Komazawa (1995), who ascribed the low-density structures to a magma reservoir or magma-related structure. The high-density structure beneath Nekodake is thought to be derived from the basaltic andesite composing Nekodake (Ono and Watanabe 1985).

The location of the southern low-density body (SLDB) corresponds to the active magma reservoir inferred from seismic velocity (Sudo and Kong 2001) and ground deformation (Sudo et al. 2006). Fumarolic activity has been continuously observed and the large eruption occurred five months after the 2016 Kumamoto earthquake at Nakadake, where the SLDB is located (Mori and Notsu 2008; Japan Meteorological Agency 2016a). Therefore, the SLDB is thought to correspond to the magma reservoir that feeds the ongoing surface activity. The persistence of volcanic activity at Nakadake supports the existence of an active magma reservoir at the SLDB, and the low density of the inferred magma reservoir is thought to result from light materials (melt with some gas) in heavier materials (phenocrysts) (e.g., Ryan 1987). The resolved low-density structure improves our 
a

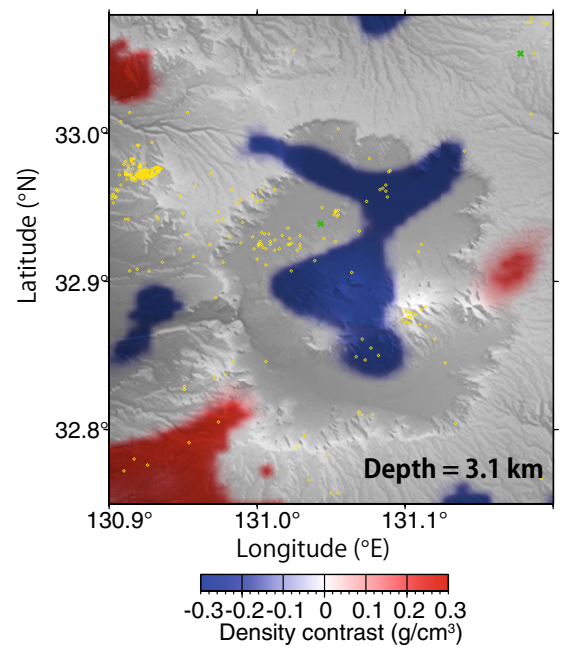

b

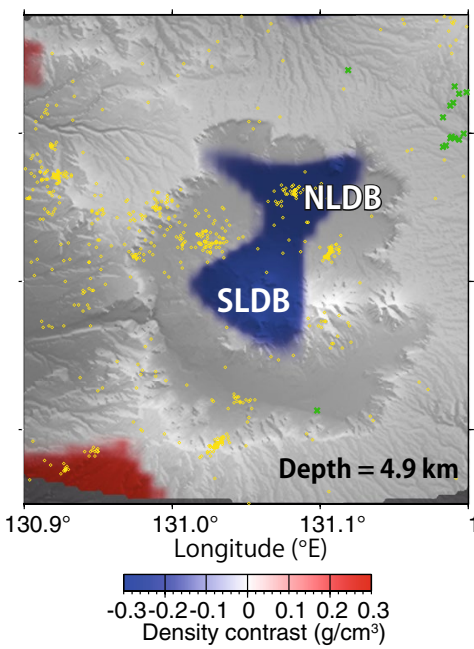

C

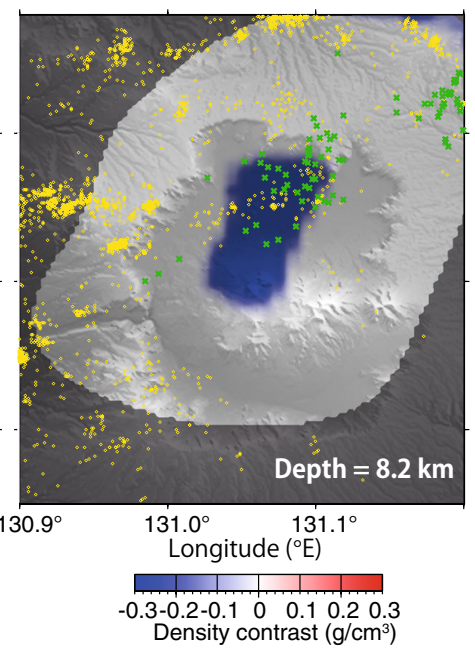

Fig. 3 Calculated density contrast model beneath Aso volcano. a, b, and c are horizontal slices at depths of 3.1, 4.9, and 8.2 km, respectively. Earthquakes within $1 \mathrm{~km}$ of the horizontal plane are plotted as yellow dots and green crosses. Yellow dots represent epicenters of earthquakes before the 2016 Kumamoto earthquake (from 2003 to 2015), determined by the JMA. Green crosses represent aftershocks that occurred in the first 3 days after the mainshock (Fig. 1). The shaded gray area in (c) is outside the modeled zone. Density distributions are plotted using linear interpolation

understanding of the thermal structure in this area, since the magma reservoir is assumed to be the heat source.

There is no evidence of current volcanic activity, including ground deformation or fumaroles, in the Asodani area, where the northern low-density body (NLDB) is located. The Asodani area has a wide, thick caldera fill comprising low-density material (Ono and Watanabe 1985; New Energy and Industrial Technology Development Organization 1996). The interpretation that lowdensity sediments fill the caldera is also supported by the short-wavelength component of the Bouguer anomaly, which reflects the shallow density structure (Komazawa 1995). Such material is rare on Kusasenri and Nakadake cones, i.e., above the SLDB. A large amount of low-density sediment at shallow depths might explain the imaged low-density body beneath Asodani. Another interpretation of the NLDB could be residues of an ancient magma reservoir, such as that which drove the caldera-forming eruption (or one corresponding to older activity).

The $\mathbf{2 0 1 6}$ Kumamoto earthquake and the low-density body We now discuss the relationship between the SLDB, which we assume is a shallow magma reservoir, aftershocks, and the rupture process of the 2016 Kumamoto earthquake. Neither the aftershocks of the 2016 Kumamoto earthquake nor seismicity before the earthquake occurs in the SLDB, though seismicity has been observed surrounding this body (Fig. 3). The location of the SLDB is consistent with the area where the mainshock rupture terminates and the edge of the fault models (Figs. 4, 5).
The rupture terminus inferred from the waveform inversion of Yagi et al. (2016) overlaps the SLDB at Fault A in Fig. 1. The fault terminus at the SLDB (Fault B in Fig. 1) is also consistent with the ground surface deformation in Aso caldera obtained from InSAR data (Fig. 5). Note that Fault B makes up one-sixth of the NE side of the total fault model (Geospatial Information Authority of Japan 2016b). Fault B crosses Aso caldera as a pure strike-slip fault (Geospatial Information Authority of Japan 2016b), and the SLDB is situated at the edge of the extensional direction of the fault slip region in the caldera.

The aseismicity of the SLDB may reflect the high temperature and/or ductile rheology of the SLDB. Aseismic magma reservoirs have been reported at a number of other volcanoes, including Mount St. Helens, WA, USA (Moran 1994), and Mt. Etna, Italy (Patanè et al. 2003). The boundary between the shallow seismic zone and the deep aseismic zone is known as the cutoff depth (Sibson 1984; Ito 1990) and is interpreted as the brittle-ductile transition in the crust (Brace and Kohlstedt 1980; Sibson 1982). Previous studies suggest a close relationship between cutoff depth and thermal structure, although an exact value for the former depends on many factors, including temperature, pore fluid pressure, and strain rate (Kobayashi 1977; Sibson 1986; Tse and Rice 1986; Pasquale et al. 1997; Scholz 1998). Therefore, the cutoff depth in Japan is shallow near active volcanoes with areas of high heat flow (Ito 1993; Omuralieva et al. 2012). Magnetic anomaly data suggest the existence of a hightemperature zone $\left(T>500{ }^{\circ} \mathrm{C}\right)$ beneath Aso volcano 


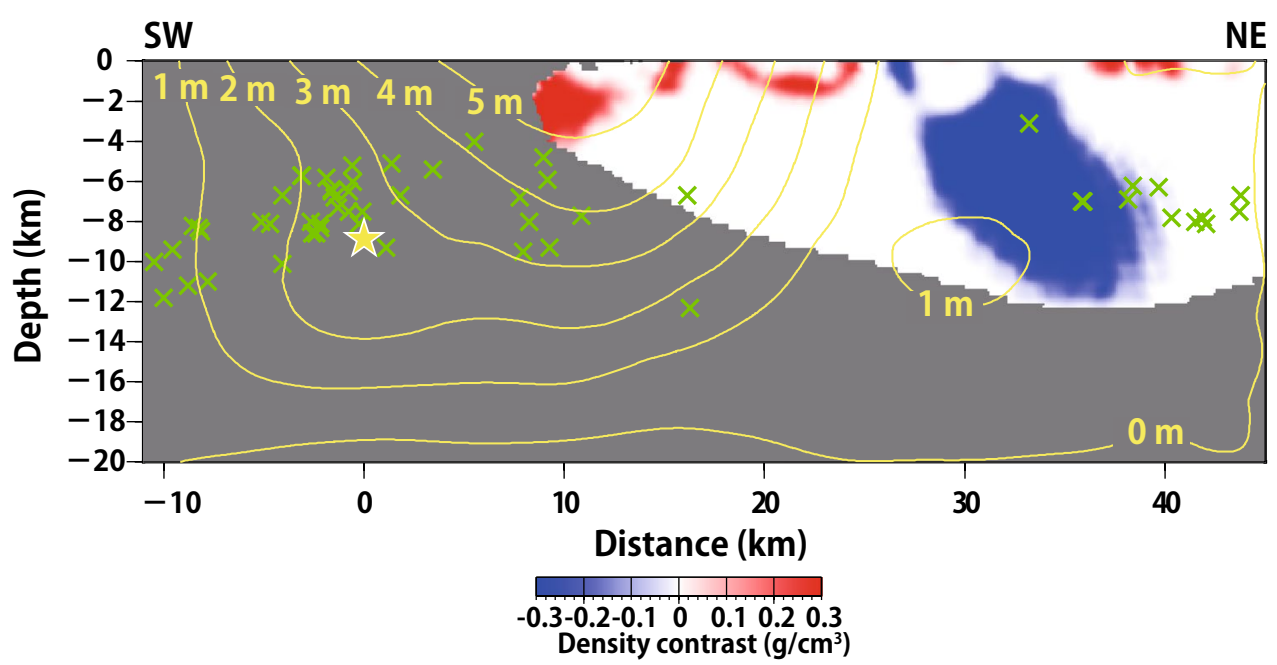

Fig. 4 Calculated density contrast model projected on the hypothetical fault surface model. The hypothetical fault surface model was created from the analysis of teleseismic waveform data for the 2016 Kumamoto earthquake (Yagi et al. 2016). Yellow contours represent the modeled slip distribution along the fault, in meters (Yagi et al. 2016). Yellow star indicates the mainshock hypocenter determined by the JMA. Aftershocks that occurred in the first 3 days after the mainshock within $3 \mathrm{~km}$ of the imaginary fault plane are plotted as green crosses. The shaded gray area is outside the modeled zone. Density distributions are plotted using linear interpolation

(Okubo and Shibuya 1993; Okubo et al. 1997). Thus, the high temperature of the magma reservoir results in the aseismicity of the SLDB. Furthermore, the mixture of gas, melt, and crystals that causes the low density of the SLDB also contributes to the aseismicity. The presence of gas and melt controls the viscous-brittle transition in solids (Cordonnier et al. 2012; Pistone et al. 2015), and a magma reservoir with a high melt fraction behaves as a viscous fluid (Lejeune and Richet 1995). The rheology of a melt-rich magma reservoir is also consistent with the aseismicity within the SLDB.

The termination of the rupture in the Aso caldera is affected by the magma reservoir imaged as the SLDB. Yagi et al. (2016) obtained a maximum slip area stably centered around $10 \mathrm{~km}$ northeast of the epicenter, and this position was robust to assumed model parameters, leading to the suggestion that the high temperature of the magma reservoir might promote plastic deformation and inhibit dynamic rupture propagation (e.g., Scholz 1998). Our results support this interpretation, as the location of the magma reservoir is consistent with the rupture termination area. Furthermore, the viscous rheology of the mixture of gas, melt, and crystals, which causes the low density of the SLDB, also contributes to the termination of the rupture: A viscous rheology inhibits rupture beneath the caldera. The location of the SLDB explains the terminus of the rupture (Fig. 4) and suggests that the fault in Aso caldera (Fault B) is unlikely to slip or propagate (Fig. 5). In fact, other fault models (Himematsu and Furuya 2016) can explain the ground deformation observed by ALOS-2/PALSAR-2 without any faults in Aso caldera, where Fault $B$ is proposed to occur.

It is interesting that aftershock activity, possibly triggered by perturbation of the stress field, is high in the NLDB. Seismicity before the 2016 Kumamoto earthquake was also observed in the NLDB. The absence of obvious volcanic activity in the Asodani area, including steam emissions, suggests that the NLDB is not a hightemperature zone; indeed, the presence of seismicity indicates that it is brittle. Lower-temperature conditions promote the crystallization and solidification of partial melt in the magma reservoir during cooling; thus, the NLDB is thought to be a mush magma, where crystallinity is high (Marsh 1996), or a very high-crystallinity magma reservoir. Mush magma has a critical point in crystallinity (50-55\%), at which the rheology shifts from viscous to rigid (Marsh 1996). The high seismicity of aftershocks in the NLDB suggests a brittle rheology and a very high-crystallinity magma reservoir, which could be the remnant of an ancient magma reservoir. Otherwise, the mush magma beneath the Asodani area may not be needed if the large amount of low-density sediment at shallow depths in the Asodani area could generate such a low-density body in the inversion process.

\section{Conclusions}

Using three-dimensional inversion of gravity data, we resolved a low-density structure that likely represents the active magma reservoir of Aso volcano, the presence of 


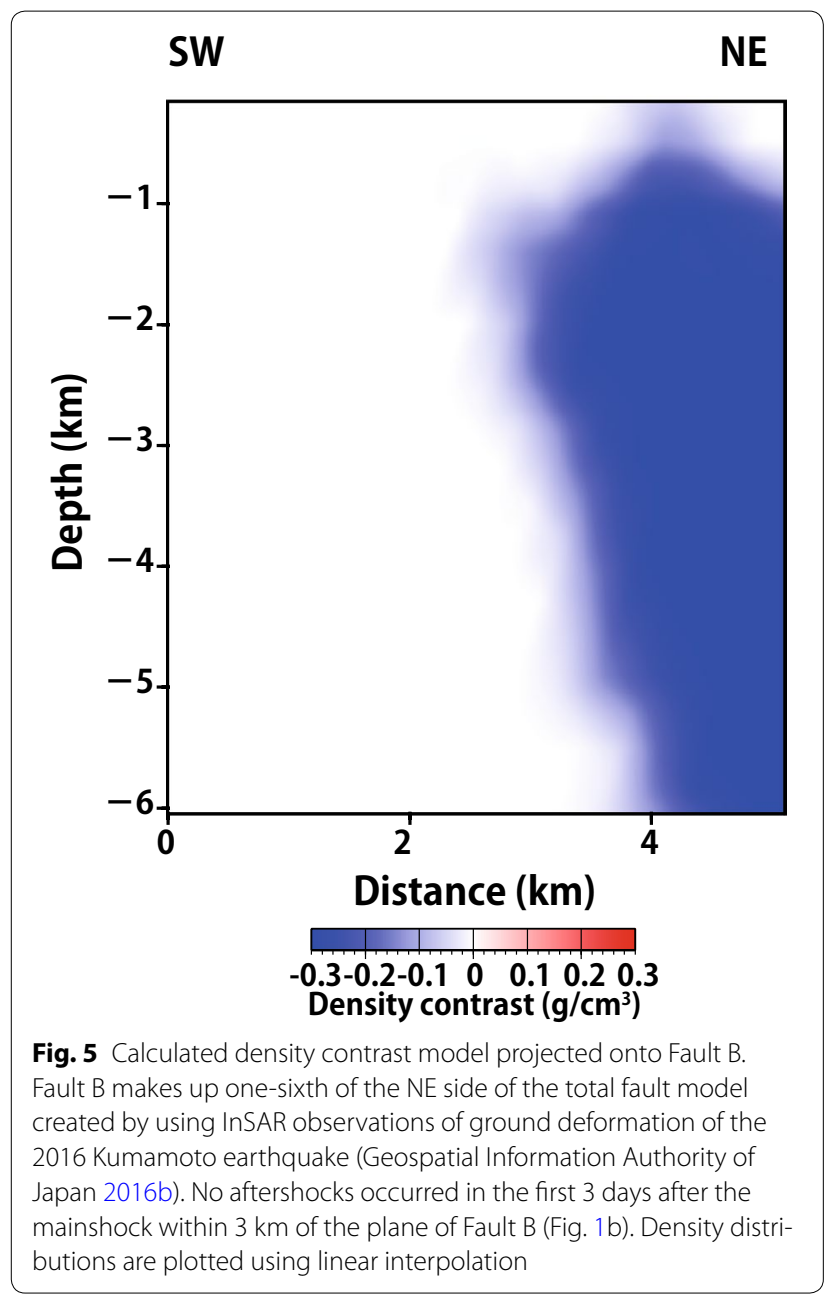

which is thought to have terminated the rupture of the 2016 Kumamoto earthquake. The location of the SLDB is consistent with the position of a shallow magma reservoir reported in previous studies. Consequently, the SLDB is a low-density magma reservoir composed of light materials (partial melt and gas) beneath Aso volcano. The absence of seismicity in the SLDB, including aftershocks, indicates the high temperature and/or ductile nature of the magma reservoir; these aseismic characteristics explain why the 2016 Kumamoto earthquake rupture terminated here. The fault beneath Aso volcano that caused the observed local ground deformation was prevented from extending to the northeast by this reservoir. We, therefore, conclude that the magma reservoir(s) beneath Aso volcano strongly influenced the rupture process and aftershock patterns of the 2016 Kumamoto earthquake. A future study will examine the relationship between the 2016 Kumamoto earthquake and the large eruption of Aso volcano at Nakadake (where the SLDB is located) following the earthquake.
The NLDB was resolved in the Asodani area, where evidence for present-day volcanic activity is scarce. Therefore, the NLDB might result from thick sediment filling the caldera, or mush magma or a very high-crystallinity magma reservoir representing the residue of an ancient magma reservoir. The high aftershock activity observed in the NLDB area is supposed to reflect the volcanic structure beneath Asodani.

Imaging a magma reservoir based only on gravity data has limitations. The exact boundaries of the density anomaly cannot be determined, owing to the uncertainty of the parameters in this study. Combining this data set with other geophysical observations (e.g., resistivity, seismic velocity) will improve the images of the magma reservoir and the fault; hence, the relationship between the fault and magma reservoir will be discussed more quantitatively in future work.

\section{Additional files}

Additional file 1: Figure S1. Co-seismic surface deformation observed by Multiple Aperture Interferometry (MAI) analysis using ALOS-2/PALSAR-2 data (modified after Geospatial Information Authority of Japan 2016a).

Blue and red areas represent forward (roughly south) and backward (roughly north) horizontal deformation with respect to the flight direction. These analyses were performed by the Geospatial Information Authority of Japan from ALOS-2 raw data measured by the Japan Aerospace Exploration Agency.

Additional file 2: Figure S2. Calculated density contrast models beneath Aso volcano in horizontal slices at depths of $3.1,4.9$, and $8.2 \mathrm{~km}$ : (a), (b), (c), (d), (e), and (f) correspond to density contrasts of $\pm 0.15, \pm 0.20$ $\pm 0.25, \pm 0.30, \pm 0.35$, and $\pm 0.40 \mathrm{~g} / \mathrm{cm}^{3}$, respectively (Additional file 5 : Table S1).

Additional file 3: Figure S3. Calculated density contrast model beneath Aso volcano in horizontal slices at depths of 3.1, 4.9, and $8.2 \mathrm{~km}$ : (a), (b), (c), and (d) were generated using homogeneity parameters of $0.2,0.4,0.6$, and 0.8 , respectively (Additional file 5: Table S2).

Additional file 4: Figure S4. Calculated density contrast model beneath Aso volcano in horizontal slices at depths of $3.1,4.9$, and $8.2 \mathrm{~km}$ : (a), (b), and (c) use mean grid lengths of 500, 750, and $1000 \mathrm{~m}$, respectively (Additional file 5: Table S3).

Additional file 5: Table S1. Inversion parameters for Additional file 2: Figure S2. Table S2. Inversion parameters for Additional file 3: Figure S3. Table S3. Inversion parameters for Additional file 4: Figure S4.

\section{Abbreviations}

JMA: Japan Meteorological Agency; InSAR: interferometric synthetic aperture radar; SLDB: southern low-density body; NLDB: northern low-density body.

\section{Authors' contributions}

AM supervised the study and drafted the manuscript. TS assisted with analysis of the inversion data and contributed to the interpretation and discussion of the results. $\mathrm{OY}, \mathrm{RO}, \mathrm{MO}, \mathrm{SU}$, and $\mathrm{YY}$ contributed to the interpretation and discussion of the results. All authors read and approved the final manuscript.

\section{Author details}

${ }^{1}$ Geological Survey of Japan, AIST, 1-1-1 Higashi, Tsukuba, Ibaraki 3058567, Japan. ${ }^{2}$ Graduate School of Life and Environmental Sciences, University of Tsukuba, 1-1-1 Tennodai, Tsukuba, Ibaraki 3058572, Japan. ${ }^{3}$ Civil Engineering Research Laboratory, Central Research Institute of Electric Power Industry, 1646 Abiko, Abiko City, Chiba Prefecture 2701194, Japan. ${ }^{4}$ Faculty of Life 
and Environmental Sciences, University of Tsukuba, 1-1-1 Tennodai, Tsukuba, Ibaraki 305-8572, Japan.

\section{Acknowledgements}

Figures were generated using Generic Mapping Tools (Wessel and Smith 1998). The topography underlying Figs. 1, 2, and 3 was derived from NASA's Shuttle Radar Topography Mission (SRTM; Farr et al. 2007). We thank Prof. Martha Savage (Editor of Earth, Planets, and Space) and two anonymous reviewers who provided constructive reviews that greatly improved the manuscript. We thank Prof. T. Yoshida, Dr. M. Komazawa, Dr. H. Hoshizumi, Dr. S. Takakura, Dr. N. Matsushima, Dr. M. Hata, Dr. N. Geshi, Dr. I. Miyagi, Dr. S. Kinoshita, and Dr. K. Nawa for useful information. This study was supported by Grant-in-Aid for Scientific Research (26109003) from the Ministry of Education, Culture, Sports, Science, and Technology (MEXT) to MO.

\section{Competing interests}

The authors declare that they have no competing interests.

Received: 9 July 2016 Accepted: 3 December 2016

Published online: 30 December 2016

\section{References}

Brace W, Kohlstedt D (1980) Limits on lithospheric stress imposed by laboratory experiments. J Geophys Res 85:6248-6252

Camacho AG, Nunes JC, Ortiz E, França Z, Vieira R (2007) Gravimetric determination of an intrusive complex under the Island of Faial (Azores): some methodological improvements. Geophys J Int 171 (1):478-494

Camacho AG, Fernández J, Gottsmann J (2011) The 3-D gravity inversion package GROWTH2.0 and its application to Tenerife Island, Spain. Comput Geosci 37:621-633

Cordonnier B, Caricchi L, Pistone M, Castro J, Hess KU, Gottschaller S, Manga M, Dingwell DB, Burlini L (2012) The viscous-brittle transition of crystalbearing silicic melt: direct observation of magma rupture and healing. Geology 40(7):611-614

Ehara S (1984) Seismic wave attenuation beneath geothermal areas in central Kyushu, Japan. Trans Geotherm Resour Council 8:489-492

Farr TG, Rosen PA, Caro E, Crippen R, Duren R, Hensley S, Kobrick M, Paller M, Rodriguez E, Roth L, Seal D, Shaffer S, Shimada J, Umland J, Werner M, Oskin M, Burbank D, Alsdorf D (2007) The shuttle radar topography mission. Rev Geophys 45:RG2004. doi:10.1029/2005RG000183

Geological Survey of Japan (2013) Gravity Database of Japan. DVD edition, Digital Geoscience Map P-2, Geological Survey of Japan, AIST, Japan

Geospatial Information Authority of Japan (2016a) The 2016 Kumamoto Earthquake: crustal deformation around the faults. http://www.gsi.go.jp/cais/ topic160428-index-e.html. Accessed 23 June 2016

Geospatial Information Authority of Japan (2016b) Information about the 2016 Kumamoto Earthquake, GSI. http://www.gsi.go.jp/common/000140781. pdf. Accessed 23 June 2016 (in Japanese)

Himematsu Y, Furuya M (2016) Fault source model for the 2016 Kumamoto earthquake sequence based on ALOS-2/PALSAR-2 pixel-offset data: evidence for dynamic slip partitioning (EPSP-D-16-00163). Earth Planets Space 68(1):169. doi:10.1186/s40623-016-0545-7

Ito K (1990) Regional variations of the cutoff depth of seismicity in the crust and their relation to heat flow and large inland-earthquakes. J Phys Earth 38:223-250

Ito K (1993) Cutoff depth of seismicity and large earthquakes near active volcanoes in Japan. Tectonophys 217:11-21

Japan Meteorological Agency (2016a) Explanatory material of volcanic activity in Aso volcano (released on 8 October 2016 at 04:30 JST). http:// www.data.jma.go.jp/svd/vois/data/tokyo/STOCK/monthly_v-act_doc/ fukuoka/16m10/20161008_503_2.pdf. Accessed 13 Oct 2016 (in Japanese)

Japan Meteorological Agency (2016b) Aso (April 2016 Issue). Monthly commentary document on volcanic activity. http://www.data. jma.go.jp/svd/vois/data/tokyo/STOCK/monthly_v-act_doc/ fukuoka/16m04/503_16m04.pdf. Accessed 13 Oct 2016 (in Japanese))
Japan Meteorological Agency (2016c) Aso (May 2016 Issue). Monthly commentary document on volcanic activity. http://www.data. jma.go.jp/svd/vois/data/tokyo/STOCK/monthly_v-act_doc/ fukuoka/16m05/503_16m05.pdf. Accessed 13 Oct 2016 (in Japanese)

Kamata H, Kodama K (1994) Tectonics of an arc-arc junction: an example from Kyushu Island at the junction of the Southwest Japan Arc and the Ryukyu Arc. Tectonophysics 233:69-81

Kobayashi Y (1977) A relationship between the distribution of focal depth of micro-earthquakes and surface heat flow in the southwestern Japan and central Japan. In: Proceedings of the symposium of earthquake prediction research, 1976. National Committee of Geophysics and Seismological Society of Japan, pp 184-193 (in Japanese with English abstract)

Komazawa M (1988) A gravimetric terrain correction method by assuming an annular prism model. J Geod Soc Jpn 34:11-23

Komazawa M (1995) Gravimetric analysis of Aso volcano and its interpretation. J Geod Soc Jpn 41:17-45

Komazawa M (1998) Gravity survey. In: Society of exploration geophysicists of Japan (ed) Handbook of methods in exploration geophysics, vol 8. Society of Exploration Geophysics of Japan, Tokyo, pp 433-471 (in Japanese)

Komazawa M, Hiroshima T, Ishihara T, Murata Y, Yamazaki T, Joshima M, Makino M, Morijiri R, Nawa K, Okuma S, Satoh H, Sugihara M, Nishimura K, Kanaya H, Shichi R, Kishimoto K, Kikawa E, Mishina M (2013) Gravity measurements data file of the geological survey of Japan. In: Geological survey of Japan gravity database of Japan. DVD edition, Digital Geoscience Map P-2, Geological Survey of Japan, AIST, Japan

Lejeune A-M, Richet P (1995) Rheology of crystal-bearing silicate melts: an experimental study at high viscosities. J Geophys Res 100:4215-4229

Marsh BD (1996) Solidification fronts and magmatic evolution. Mineral Mag 60:5-40

Matsumoto S, Nakao S, Ohkura T, Miyazaki M, Shimizu H, Abe Y, Inoue H, Nakamoto M, Yoshikawa S, Yamashita Y (2015) Spatial heterogeneities in tectonic stress in Kyushu, Japan and their relation to a major shear zone. Earth Planets Space 67(1):172. doi:10.1186/s40623-015-0342-8

Metal Mining Agency of Japan (2013) Gravity Measurements Data File of the Metal Mining Agency of Japan. In: Geological survey of Japan Gravity Database of Japan. DVD edition, Digital Geoscience Map P-2, Geological Survey of Japan, AIST, Japan

Moran SC (1994) Seismicity at Mount St. Helens, 1987-1992: evidence for repressurization of an active magmatic system. J Geophys Res 99:4341-4354

Mori T, Notsu K (2008) Temporal variation in chemical composition of the volcanic plume from Aso volcano, Japan, measured by remote FT-IR spectroscopy. Geochem J 42:133-140

New Energy and Industrial Technology Development Organization (1996) Geothermal development promotion survey in the western region of Aso Volcano. New Energy and Industrial Technology Development Organization, Japan (in Japanese)

New Energy and Industrial Technology Development Organization (2013) Gravity Measurements Data File of the New Energy and Industrial Technology Development Organization. In: Geological survey of Japan Gravity Database of Japan. DVD edition, Digital Geoscience Map P-2, Geological Survey of Japan, AIST, Japan

Okubo Y, Shibuya A (1993) Thermal and crustal structure of the Aso volcano and surrounding regions constrained by gravity and magnetic data, Japan. J Volcanol Geotherm Res 55:337-350

Okubo Y, Kanaya H, Shibuya A, Okumura K (1997) Origin of a magnetic lineation on Kyushu Island, Japan. Island Arc 6:386-395

Omuralieva AM, Hasegawa A, Matsuzawa T, Nakajima J, Okada T (2012) Lateral variation of the cutoff depth of shallow earthquakes beneath the Japan Islands and its implications for seismogenesis. Tectonophysics 518:93-105

Ono K, Watanabe K (1985) Geological map of Aso volcano, geological map of volcanoes 4. Geological Survey of Japan, Japan

Pasquale V, Verdoya M, Chiozzi P, Ranalli G (1997) Rheology and seismotectonic regime in the northern central Mediterranean. Tectonophysics 270:239-257

Patanè D, De Gori P, Chiarabba C, Bonaccorso A (2003) Magma ascent and the pressurization of Mount Etna's volcanic system. Science 299:2061-2063 
Pistone M, Cordonnier B, Caricchi L, Ulmer P, Marone F (2015) The viscous to brittle transition in crystal- and bubble-bearing magmas. Front Earth $\mathrm{SCl}$ 3.71 doi:10.3389/feart 2015.00071

Research group for active faults of Japan (1991) Active faults in Japan. Sheet maps and inventories, revised edn. University of Tokyo Press, Tokyo

Ryan MP (1987) Neutral buoyancy and the mechanical evolution of magmatic systems. In: Mysen BO (ed) Magmatic processes: physicochemical principles, vol 1. Geochemical Society, University Park, pp 259-287

Scholz CH (1998) Earthquake and friction laws. Nature 391:37-42. doi:10.1038/34097

Sibson RH (1982) Fault zone models, heat flow, and the depth distribution of earthquakes in the continental crust of the United States. Bull Seismol Soc Am 72:151-163

Sibson RH (1984) Roughness at the base of the seismogenic zone: contributing factors. J Geophys Res 89:5791-5799

Sibson RH (1986) Earthquakes and rock deformation in crustal fault zones. Ann Rev Earth Plan Sci 14:149-175

Sudo Y (1988) Upper crustal structure of Aso Caldera, Kazan. Bull Volcanol Soc Jpn 33:130-134 (in Japanese)
Sudo Y (1991) An attenuation structure beneath the Aso Caldera determined from the propagation of seismic waves. Bull Volcanol 53:99-111

Sudo Y, Kong L (2001) Three-dimensional seismic velocity structure beneath Aso Volcano, Kyushu, Japan. Bull Volcanol 63:326-344. doi:10.1007/ s004450100145

Sudo Y, Tsutsui T, Nakaboh M, Yoshikawa M, Yoshikawa S, Inoue H (2006) Ground deformation and magma reservoir at Aso Volcano: location of deflation source derived from long-term geodetic surveys. Bull Volcanol Soc Jpn 51:291-309 (in Japanese with English abstract)

Tanaka A, Yano Y, Sasada M (2004) Geothermal gradient data in and around Japan. Digital Geoscience Map DGM P-5, Geological Survey of Japan

Tse ST, Rice JR (1986) Crustal earthquake instability in relation to the depth variation of frictional slip properties. J Geophys Res 91:452-459

Wessel P, Smith WH (1998) New, improved version of generic mapping tools released. Eos Trans Am Geophys Union 79:579

Yagi Y, Okuwaki R, Enescu B, Kasahara A, Miyakawa A, Otsubo M (2016) Rupture process of the 2016 Kumamoto earthquake in relation with the thermal structure around Aso volcano. Earth Planets Space 68(1):1-6. doi:10.1186/ s40623-016-0492-3

\section{Submit your manuscript to a SpringerOpen ${ }^{\circ}$ journal and benefit from:}

- Convenient online submission

- Rigorous peer review

- Immediate publication on acceptance

- Open access: articles freely available online

- High visibility within the field

- Retaining the copyright to your article 